\title{
APPLICATION OF SOFTWARES FOR DRILLING AND BLASTING
}

\author{
Milanović Stefan ${ }^{1}$, Kričak Lazar ${ }^{1}$, Negovanović Milanka ${ }^{1}$, \\ Simić Nikola ${ }^{1}$, Marković Jovan ${ }^{1}$
}

Received: May 23, 2019

Accepted: June 14, 2019

\begin{abstract}
Nowadays, software is increasingly used in mining through the exploitation of mineral raw materials, mine design, in performing various field operations, etc. Among mining software, there is software for specific mining operations such as drilling and blasting operations. These processes are very important in the exploitation of solid mineral raw materials because they represent the cheapest and most effective form of rock mass fragmentation. Through the Paper, some of software is presented in the combination with modern technologies that are in use all over the world which have brought great advantages in drilling and blasting operations.
\end{abstract}

Keywords: software; modern technologies; blasting; drilling; blast field

\section{INTRODUCTION}

The need of software application in mining is becoming more and more important and brings significant advantages both in mine designing and in the exploitation of mineral raw material deposits. In the world large number of surface and underground mines has being opened. Each process starting from the preparation and opening of the mineral deposit to the obtaining the final product requires efficient and accurate monitoring.

The application of software for this purpose significantly gives advantage in the field of mine design, optimisation, field monitoring, etc., by shortening the time required to perform these operations and providing the ability to dispose of the precise data.

During the exploitation of deposits of solid mineral raw materials, very important phases are drilling and blasting, which are the most efficient and cheapest methods of the fragmentation of hard rocks. Drilling and blasting of rocks represent very complex processes that require a lot of attention during performance in order to minimize unwanted effects, such as ground vibration, airblast, flyrock, etc. Blasting results depend

\footnotetext{
${ }^{1}$ University of Belgrade - Faculty of Mining and Geology, Belgrade, Serbia Emails: stefan.milanovic@ @rgf.rs, lazar.kricak@rgf.bg.ac.rs, milanka.negovanovic@rgf.bg.ac.rs, nikola.simic1991@rgf.rs, jovan.markovic@rgf.rs
} 
on the parameters such as blast pattern, burden size, borehole length and stemming, bench height, etc. The use of software enables the best results of blasting operations through optimising the drilling and blasting parameters. Software also gives a better overview of the blast field through displaying terrain surfaces in 3D.

Development of the large number of software in the world has helped to obtain as precise data as possible and to get a better overview of the conditions of the rock massive before drilling and blasting works. The application of software in the combination with modern technologies such as UAV (unmanned aerial vehicle) technology or drones is also significant, because the software can finally process the precise input data from the field.

\section{TYPES OF SOFTWARE ACCORDING TO PURPOSE}

There are different types of software used in mining, which are classified into the following groups:

- software packages for general purposes: mining software for deposits modeling and design of excavation in surface and underground exploitation,

- specialized software packages for optimisation of surface and underground exploitation and the analysis of excavation mineral raw materials,

- software packages for specific purposes designed for the analysis of specific problems related to the design of surface mine or planning the technology of exploitation, for example: analysing the costs of excavation, analysing the particular technical problems in surface mine exploitation (analysis of slope stability), designing the systems of exploitation (drilling and blasting, loading and transport) and others (Miladinović M. et al., 2011).

As stated at the beginning of the Paper, the software is related to drilling and blasting operations in surface and underground exploitation of mineral raw material deposits. In further text, the detailed description of the third group of software according to the above classification will be given.

\section{SOFTWARE FOR DRILLING AND BLASTING}

There are currently a large number of specific-purpose software on the world market, i.e. software that deals with the design of drilling and blasting operations. Through this Paper some of the most common software that is very useful in these fields will be described. The method of software operation is generally similar and most software is based on field images, model design, blast field design, optimisation of drilling and blasting parameters, etc. 


\subsection{BlastMetriX 3D (3GSM)}

The innovative system JointMetriX 3D appeared in 2005, allowed 3D images to be taken from close range up to $1.500 \mathrm{~m}$, thereby facilitating the collection of data in mining and tunnelling. This software has cut the time for mapping and reproducible results leading to the extraordinary data for planning and designing the surface and underground exploitations (3gsm gmbh, 2019).

Further development was the creation of ShapeMetriX 3D used for digital rock mass characterisation including geological mapping in the tunnelling, mining industry and general geotechnical engineering.

The next step in development was the system BlastMetriX 3D for bench face profiling and blast design based on three-dimensional images (3gsm gmbh, 2019). The system is based on the use of handheld calibrated digital cameras and dedicated software that 3GSM has expanded to many countries around the world (3gsm gmbh, 2019).

BlastMetriX 3D provides a metric 3D image representing a dense three-dimensional survey of the bench surface. Using a dedicated software component the geometry of the blast field can be planned and optimised taking into account the actual bench face geometry instead the planned one. It is a system that is easily used for making bench face profiles and designing blast fields based on 3D images. The first step is to set up field markers, in order to record at least two images using the calibrated digital camera. Photos recorded by digital camera can be used to generate a 3D image of the surface of the bench face by built software. The result obtained by processing photos is a metric 3D image representing a dense three-dimensional survey of rock surface (3gsm gmbh, 2019).

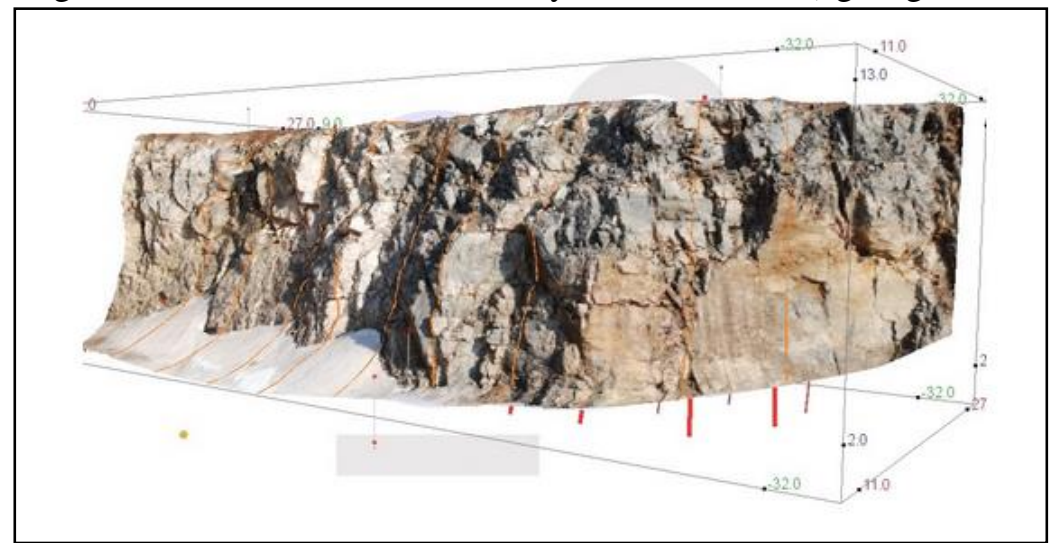

Figure $13 \mathrm{D}$ image of a bench face with planned boreholes and visualised profiles (3gsm gmbh, 2019) 
Based on the 3D image of a bench face (Figure 1) where boreholes are shown, together with their layout and profiles along the blast field, corrections can be made in the form of boreholes arrangement, angle of boreholes, burden, etc. In addition to the plan of blast pattern, the possibility of assessing the quality of the rock material is developed. Through the 3D image of a bench face, a transparent picture of the colored zones can be obtained (Figure 2) indicating where the burden is bigger (blue) or smaller (red zone), which significantly affects the effects of blasting (flyrock, fragmentation), (3gsm gmbh, 2019).

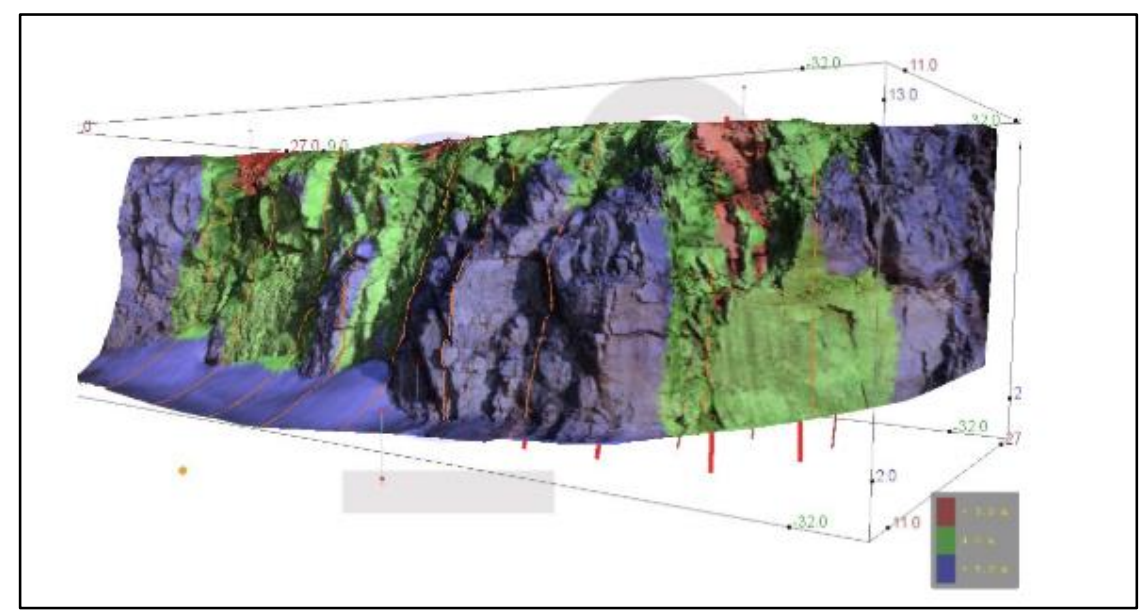

Figure 2 Colour-coded visualisation of burden over the entire bench face

(3gsm gmbh, 2019)

Using this software, the blast pattern is planned and optimised taking into account the actual dimensions of the bench, and it is also possible to calculate and correct the burden (3gsm gmbh, 2019).

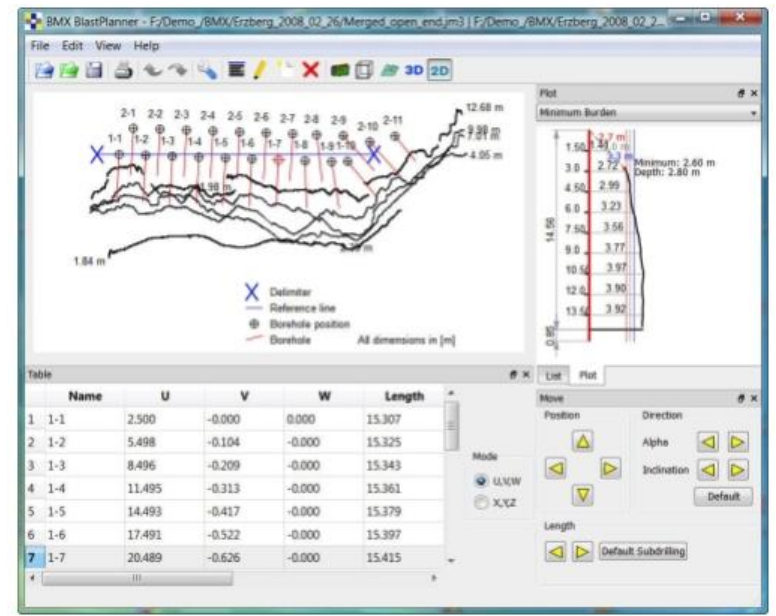

Figure 3 Software framework displaying drilling parameters and the profile of the borehole (3gsm gmbh, 2019) 
Figure 3 shows the blast pattern with the minimal size of the burden of the selected borehole as well as the drilling parameters such as the length of the borehole, slope, the position of boreholes, etc. Each borehole is individually adapted to find optimal drilling parameters in order to achieve satisfactory blasting results (3gsm gmbh, 2019).

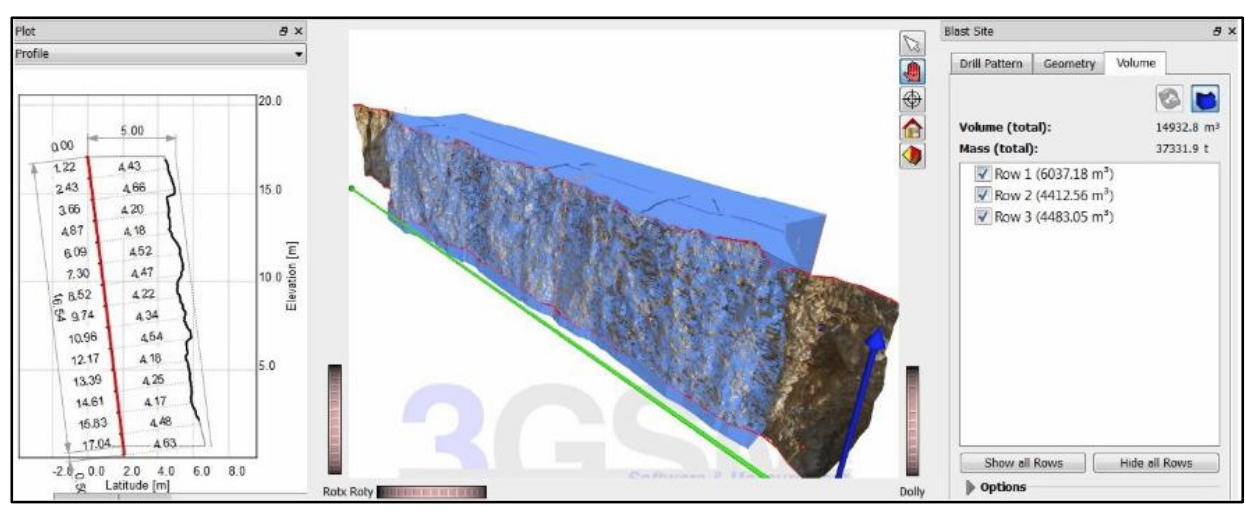

Figure 4 Bench model for calculating the volume of fragmented rock material

(3gsm gmbh, 2019)

As an additional feature, this software also offers volume calculations (Figure 4), i.e. volume of rock material that will be blasted on the projected blast field. A volume can be calculated between two different 3D models or between a 3D model and a terrain surface.

3GSM has also developed Blast Metrix UAV which enables the generation of 3D images from the air using unmanned aerial vehicle-UAV (drones) for face profiling, blast design and analysis. Aerial 3D images allow for an optimal acquisition of the blast site geometry especially of larger sites.

Aerial photography provides the possibility to survey not only the blasting site but also the whole mine with the surrounding area (Figure 5), and thus the real overview of the terrain surface is obtained (3gsm gmbh, 2019).

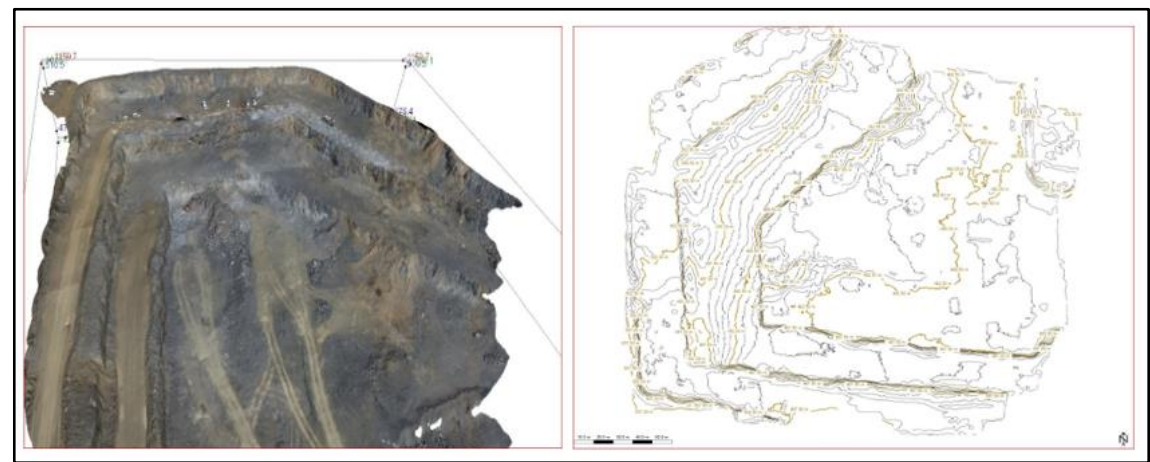

Figure 5-3D image of terrain (left) with contour plot isoline (right) obtained by UAV (3gsm gmbh, 2019) 


\subsection{O-Pitblast (O-Pitblast)}

O-Pitblast is an application software for the planning, control and optimisation of rock drilling and blasting operations. Developed by O-Pitblast Company, it fulfils all the need of blast engineers to optimise, control, reduce costs and increase safety during blasting. This platform allows the user to import terrain surface data, such as topography and rock material characteristics for blast design. This is possible due to the artificial intelligence module. In addition to all operating modules, it has a management section that allows the recording of blast data, the development of plans and mining reports, graphic display of results, monitoring technology, user control and multiple project management $(\mathrm{O}-$ pitblast, 2017).

O-Piblast software enables monitoring and analysing various parameters that affect the results of blasting. For example, many of drilling and blasting parameters, such as blast pattern, the amount of explosive charges, drill pattern influence on the fragmentation of blasted rock, whose analysis is shown in Figure 6 (O-pitblast, 2019).

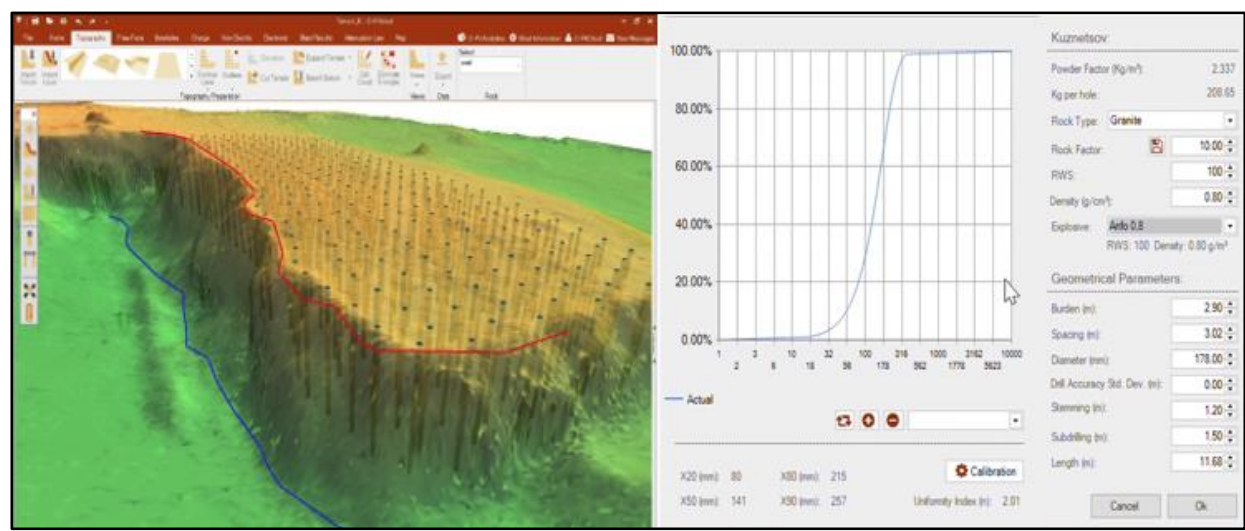

Figure 6 Software with the Kuz-Ram analysis (O-pitblast, 2019)

O-Pitblast has the tools for the determination of attenuations laws of any terrain. This information allows the prediction of ground vibration that each blast will generate. Confidence level curves (Figure 7) can be obtained according to the imported values of the parameters: peak particle velocity-PPV of each channel (longitudinal, vertical and transverse), distance from the measuring point to the blast field, vector sum). Seismic analysis enables the subsequent redesigning the blast process in order to avoid possible damages (O-pitblast, 2019). 


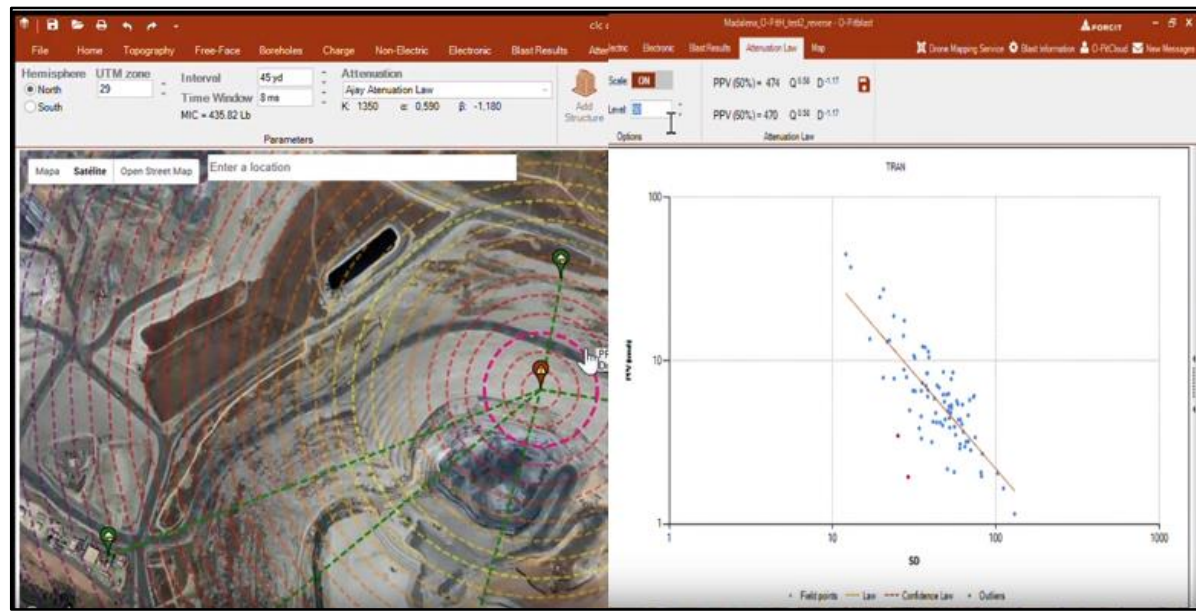

Figure 7 Analysis of seismic effect and diagram of allowed PPV (O-pitblast, 2019)

Among other tools, O-Pitblast has topography tools based on UAV technology for capturing topography information and free face profiles. This is a technology which gives a realistic picture of the terrain's surface and it is easier to plan and design a blast field (O-pitblast, 2019).

\subsection{Blades (MineExcellence)}

MineExcellence Company is represented in the drilling and blasting, mining, monitoring. It has a large number of software packages for surface and underground exploitation, as well as mobile platforms that provides overview of work, mine monitoring and availability to engineers at any time. It helps the engineer to improve and optimise drilling and blasting operation, which can result with significant benefits and eliminate potential risks during blasting. The platform is currently used by large mining companies, small mining companies, and mining service providers across countries (Mineexcellence, 2019).

The software provides a solution to the various problems that may arise during blasting, such as flyrock, airblast, seismic vibration and the fragmentation size. An innovative mobile application provides support and flexibility to the person on terrain. It also offers technologies for the use of unmanned aircraft (Figure 8) in the blasting process, which represents a new innovation that helps achieving significant results such as productivity during exploitation (Mineexcellence, 2019).

Blades has input data such as blast field coordinates, borehole diameter, blast pattern, volume and rock characteristics, face profile, borehole arrangement, desired fragmentation size, types of explosives, initiating devices and environmental constraints. Blast Designer Software (Blades) calculates the parameters of the designed blast field, 
explosives charge distribution, initiation timing and delay time, results in terms of rock breakage and fragment size distribution of blasted rock (Mineexcellence, 2019).

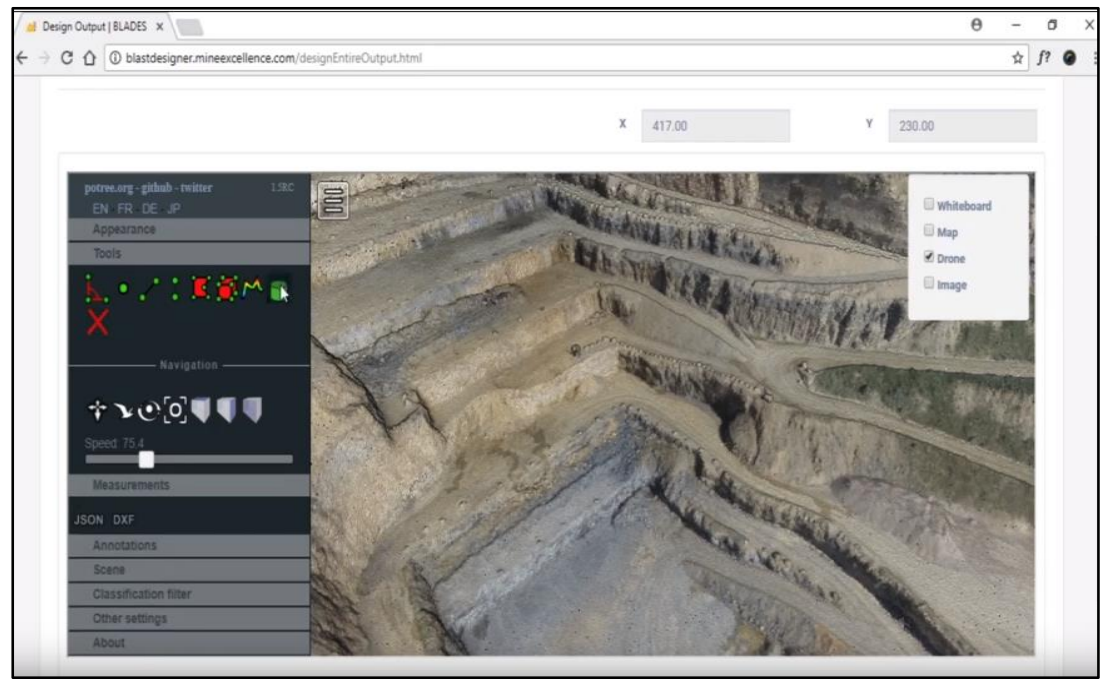

Figure 8 Terrain of open pit mine recorded with the use of UAV (Mineexcellence, 2019)

Tunnel Designer Software by MineExcellence Company is used for designing tunnels or drifts. (Figure 9). It can be used for design and development of tunnels of various shapes such as Rectangular Tunnels, Circular Tunnels, Polygonal Tunnels (Mineexcellence, 2019).

It provides with a drill pattern to meet the user requirements based on the defined hole types such as cut holes, lifter holes, perimeter holes in order to optimise the parameters and to achieve the best possible efficiency of blasting (Mineexcellence, 2019).

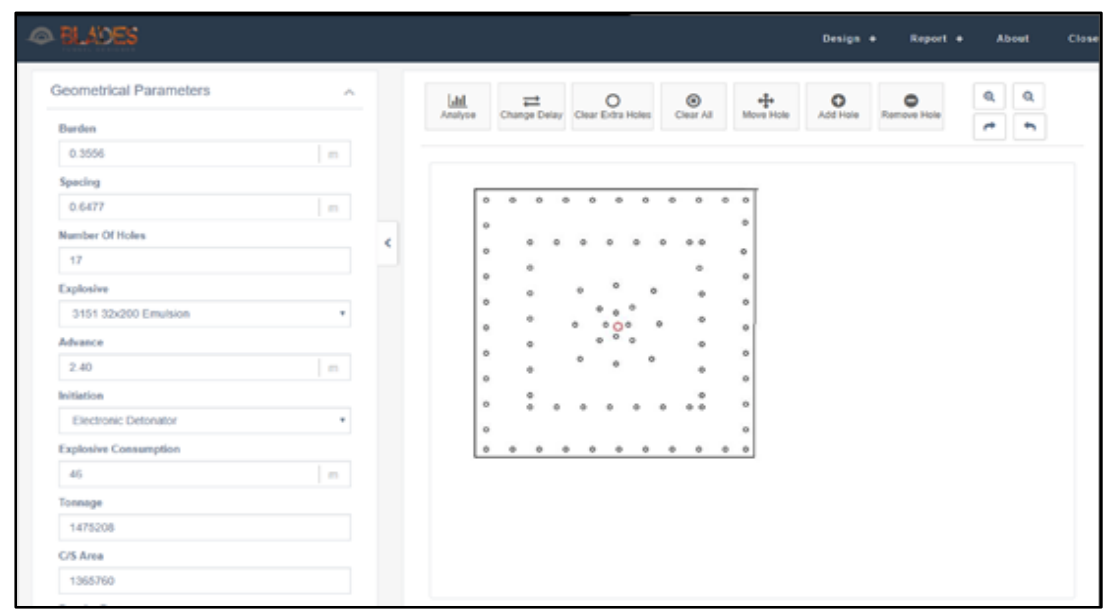

Figure 9 Blast design in underground excavation by Tunnel Designer Software (Mineexcellence, 2019) 


\subsection{SHOTplus 5 Premier (Orica)}

SHOTPlus 5 Premier software provides an opportunity for engineers to design, analyse and optimise blast. The advanced application contains extensive pyrotechnic and electronic detonator timing tools as well as comprehensive blast field design possibilities for all types of deposits. With the fifth generation of Orica's SHOTPlus technology, complex blast can be designed, numerous report types can be generated, simulations of multiple blast scenarios can be run, and the most efficient results can be predicted (Shotplus 5 premier, 2019).

The software enables designing a blast field in a full 3D environment (Figure 10). The boreholes are visible from any angle using 3D rotating tools and zoom option that allow critical areas of blast field to be viewed. Also, visualise timing tool for simulating blasting allows identifying any problem areas and confirming the blasting sequence before firing the shot (Shotplus 5 premier, 2019).

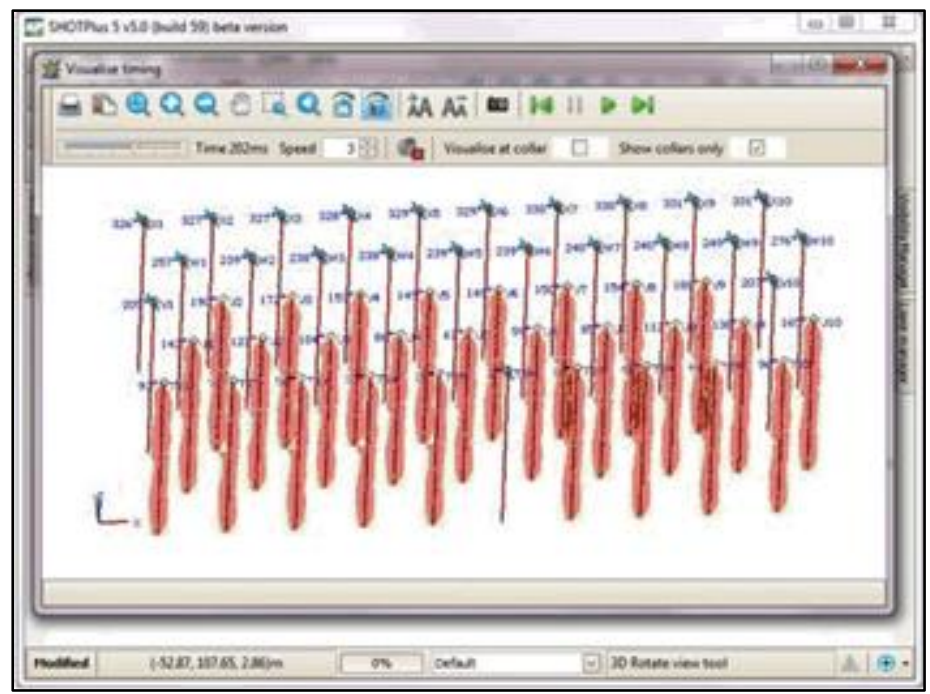

Figure 10 3D visualise timing tool for blast simulation (Shotplus 5 premier, 2019).

SHOTPlus 5 Premier creates detailed 3D surfaces (Figure 11) for accurate designing through-seam blasts with up to six intercepts in a blasthole track, or three separate seams with a top and bottom surface. The blast design can be started from the back or the front, based on desired blasting technique (Shotplus 5 premier, 2019). Borehole positions can be optimised and problems can be checked before drilling by viewing horizontal and vertical profiles. 


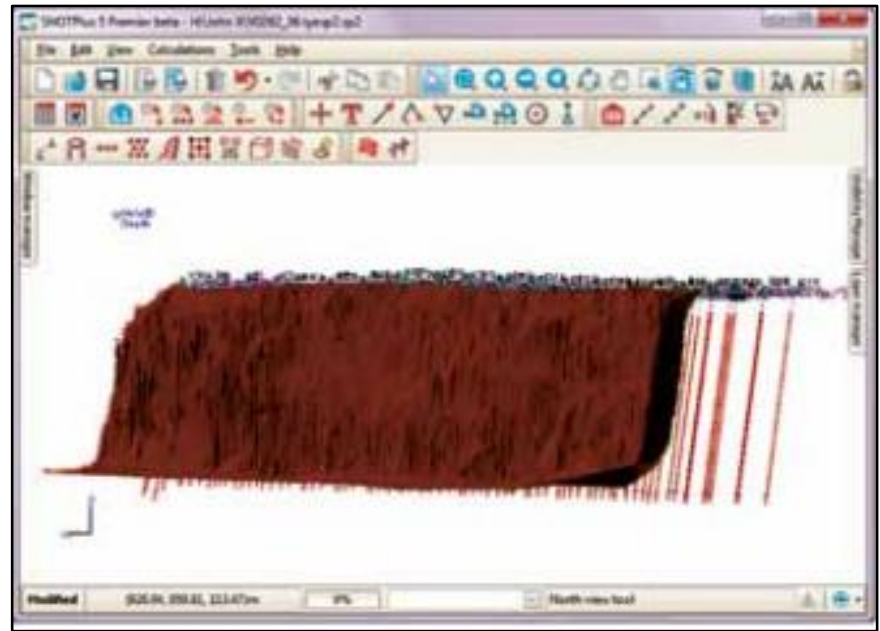

Figure 11 3D surfaces of blast field with boreholes (Shotplus 5 premier, 2019)

\subsection{BlastmapTM III (BME)}

BLASTMAP ${ }^{\text {TM }}$ III (Figure 12) has been developed through a series of generations of BME to meet the needs of clients and engineers. It represents a powerful tool to design blasts for a short time as possible. Software provides the optimisation of drilling and blasting parameters, planning, designing and analysing the blasting operations. BLASTMAP ${ }^{\mathrm{TM}}$ III enables easy design of the blast field from the layout of the boreholes to the amount of explosive charge for each borehole, deck charging and delay time (Bme, 2019).

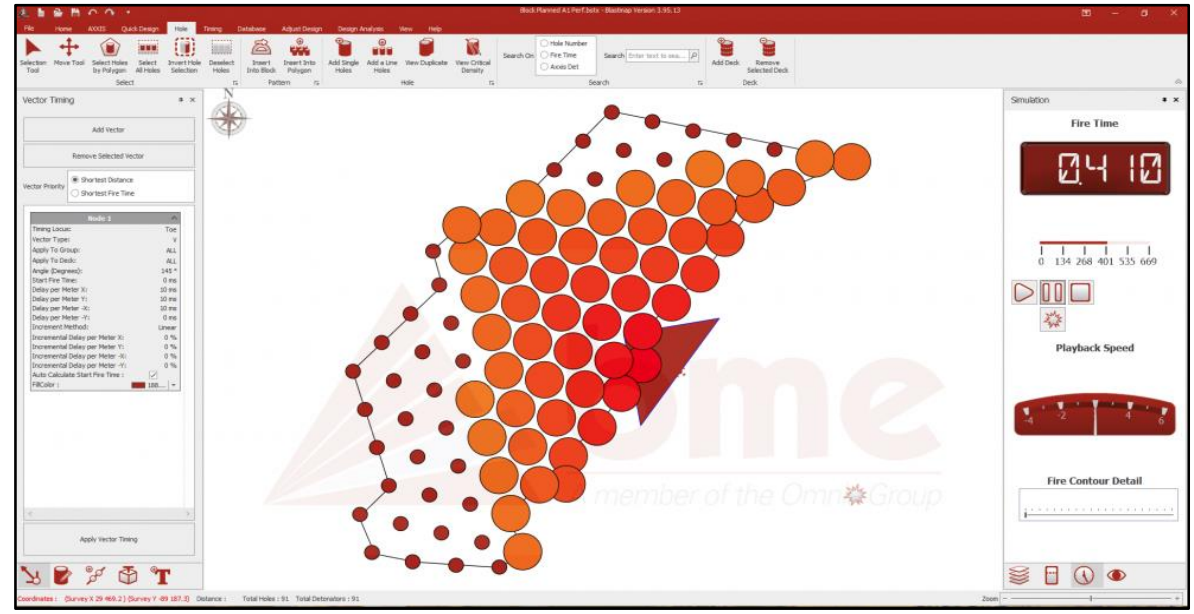

Figure 12 Blast field with designed blastholes (Bme, 2019) 


\subsection{JK SimBlast (JK Tech)}

JKSimBlast is a general-purpose software system (Figure 13) for simulation and management of blasting in mines and related operations in order to provide the best possible system for managing drilling and blasting operations. Developed by JKTech company based on more than two decades of experience from JKMRC in mining research and has more than 400 users worldwide in surface, underground and tunnelling blasting works, working in mines consulting and education. JKSimBlast can provide accurate, long-term storage of plans and results, especially where there is a need for particular database. It applies not only to mine and quarry operations, but also research, education, design, simulation, analysis, optimisation, including manipulation of models, data and results within one system (JKTech, 2019).

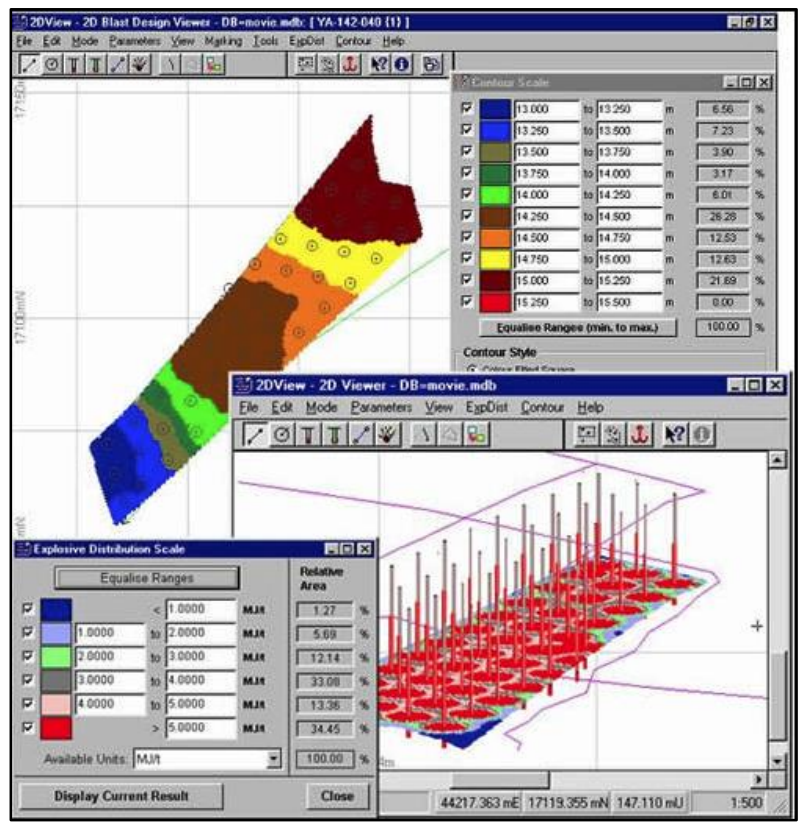

Figure 13 Workspace in JKSimBlast software (JKTech, 2019).

\section{CONCLUSION}

Mining software is used in design and modelling in surface and underground exploitation. It provides shorter time and greater efficiency for preparing operations, the preparation of reports, elaborates, project documentation. The use of software makes it much easier to work in the field and in the production process.

The use of modern technologies and software in recent years is growing, and in the domestic market there is an interest in their application. Software can control and make 
fast many processes in mining operations. It can be also used for specific purposes such as drilling and blasting, as presented in the Paper. The use of software has also greatly improved the use of modern technologies, unmanned aircraft, calibrated cameras that are used to record terrain and thus create a precise database for software. By processing the obtained data, the parameters related to drilling and blasting operations can be easily and quickly optimised.

With the software, it can be obtain transparent results based on a graphical 3D interface, where one can efficiently view all the problems and avoid the negative effects that can result from blasting. The advantages of using them are therefore large and are based on obtaining precise data that can be useful on the ground.

\section{Acknowledgement}

The authors thank the Serbian Ministry of Education, Science and Technological Development for their support on the Project of Technological Development TR33003.

\section{REFERENCES}

MILADINOVIĆ, M. et al. (2011) Computer programs for design and modelling in mining. Podzemni radovi, 19, pp. 109-124.

3GSM GMBH (2019) BlastMetrix 3D. [Online] Available from: https://3gsm.at /produkte/blast-metrix/ [Accessed 13/05/2019].

3GSM GMBH (2019) Modifications of the BlastMetrix 3D software. [Online] Available from: https://3gsm.at/services/blastmetrix-3d/ [Accessed 13/05/2019].

3GSM GMBH (2019) Aerial 3D imaging. [Online] Available from: https://3gsm.at /produkte/blastmetrix-uav/ [Accessed 13/05/2019].

O-PITBLAST (2017) User manual. [Online] Available from: https://forcit.fi lassets/Uploads/O-Pitblast-Manual-v1.3.0.pdf [Accessed 13/05/2019].

O-PITBLAST (2019) Blast design software. [Online] Available from: https://www.opitblast.com/ [Accessed 13/05/2019].

MINEEXCELLENCE (2019) Mining Software Solutions for the Mining industry in Australia and India. [Online] Available from: https://www.mineexcellence.com/ [Accessed 13/05/2019].

MINEEXCELLENCE (2019) Blades. [Online] Available from: https://www.mine excellence.com/blast-design-software/ [Accessed 13/05/2019]. 
MINEEXCELLENCE (2019) Blast Designer for tunnel or drifts. [Online] Available from: https://www.mineexcellence.com/blades-tunnel-designer/ [Accessed 13/05/2019].

SHOTPLUS 5 PREMIER (2019) Advanced blast design software. [Online] Available from: https://www.oricaminingservices.com/uploads/SHOTPlus\%205\%20brochure.pdf [Accessed 13/05/2019].

BME (2019) Blastmap III. [Online] Available from: http://www.bme.co.za/products /software/blast-map3 [Accessed 13/05/2019].

JKTECH (2019) JK Sim Blast. [Online] Available from: https://jktech.com.au /jksimblast [Accessed 13/05/2019]. 